
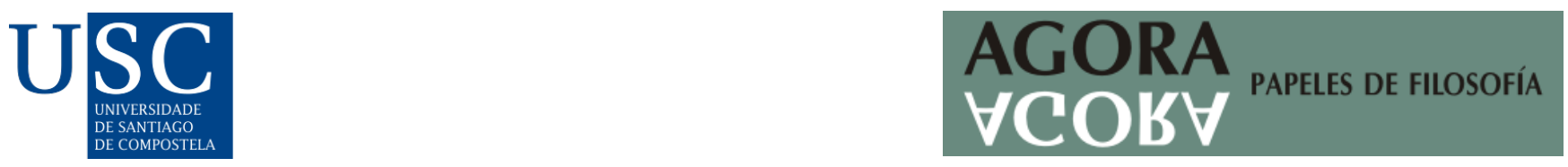

Agora. Papeles de Filosofía, 41(1), 2022. ISSN-e: 2174-3347

https://doi.org/10.15304/agora.41.1.7648

Recensiones

\title{
BUTLER, Judith: La fuerza de la no violencia, traducción de Marcos Mayer, Paidós, Buenos Aires, 2020, 256p.
}

\author{
Emilia Martin
}

Recibido: 17/04/2021; Aceptado: 03/05/2021

La fuerza de la no violencia, aparecido originalmente en inglés en febrero de 2020 (The Force of Nonviolence), reúne textos que en diferentes versiones han sido publicados o presentados en conferencias por Judith Butler a lo largo de los cuatro años anteriores. Las inquietudes del libro están en directa continuidad con sus producciones teóricas previas. La autora interroga aquí sobre los modos de representación que disponemos para aprehender la vida y las fuerzas que amenazan su existencia. Toma como punto de partida un mundo saturado de violencia y su trabajo gira en torno a hallar maneras de vivir en él donde esa potencia pueda ser controlada, reducida o redirigida. Su apuesta fuerte es la afirmación de un compromiso con una postura de la no violencia.

El libro consta de una introducción, cuatro capítulos y se completa con una posdata. En el primer capítulo, "La no violencia, la duelidad y la crítica al individualismo", la filósofa propone tres tesis centrales. En primer lugar, postula la no violencia como una forma activa de resistencia. Con ello se opone a la idea generalizada que asocia primeramente la no violencia con una actitud pasiva del no hacer, una elección moral individual, sobre la que se asientan las críticas que le atribuyen, o bien ingenuidad, o bien privilegio en circunstancias en que la violencia parece abarcarlo todo y no dejar alternativas. Por otra parte, esta comprensión del fenómeno le permite a Butler reforzar la distinción entre violencia y agresión. Así, un compromiso con la no violencia puede ser expresión de la ira o la indignación y, a veces, exige ser sostenido agresivamente.

La segunda tesis consiste en señalar la relación indisociable entre la postura asumida de la no violencia y una noción de igualdad no individualista. Para ello, la autora despliega una crítica a la idea de sujeto supuesta en la representación clásica del estado de naturaleza. Las historias que presenta comienzan con un individuo ya constituido cuyos atributos centrales son la masculinidad, la adultez y la autosuficiencia. De este modo, estas descripciones tradicionales aniquilan las partes de la historia que nos cuentan a través de qué procesos alguien llega a ser un individuo con tales propiedades y, con ello, se borra toda dependencia, tanto de otras criaturas humanas como de todo ambiente o infraestructura. Frente a esta comprensión de las cosas, la interdependencia aparece como una alternativa para pensar la constitución de la subjetividad. Esta dependencia mutua es formulada como un rasgo de todo vínculo social. Y es a la vez una condición para postular una igualdad que no se condice con un derecho individual. Aquello que hace iguales a las vidas es su duelidad, un principio en el que Butler insiste en reiteradas ocasiones. Con ello quiere significar que toda vida debe ser duelable, esto es, merece ser llorada y su pérdida, lamentada. A través de esta 
propuesta es posible para la autora plantear obligaciones sociales y globales recíprocas sostenidas en su modo particular de entender la solidaridad.

En tercer lugar, Butler se esfuerza en demostrar que la norma por la cual se justifica la excepción de la autodefensa frente a la prohibición de matar es al mismo tiempo un criterio para distinguir entre grupos que estamos y que no estamos dispuestos a duelar. Al apelar a la defensa propia -cuyos límites se pueden extender a mis seres queridos, a mis cercanos, e incluso a una población o nación entera-, se justifica la propia violencia, que luego es transferida, ocultada y autorizada. Las fantasías que operan en la base de esta justificación habilitan el racismo y la destrucción de poblaciones. Butler recurre al psicoanálisis para examinar cómo se entretejen estas formas fantasmáticas en las discusiones políticas sobre la igualdad y la violencia, formas que se constituyen como una dimensión acrítica en que se presentan como racionales ciertas opciones morales.

En diálogo con lo planteado anteriormente, en el segundo capítulo, "Preservar la vida del otro", Butler rescata de la teoría psicoanalítica la crítica del “yo” que permite abrirlo a una concepción más amplia donde la propia vida ya está vinculada a otra vida en una relación que las precede. La base de la ética butleriana supone entonces que la preservación de la propia vida y la preservación de otro no son completamente separables. Se trata de un "yo" ambiguo que mantiene relaciones conflictivas y cuya diferenciación es problemática. Así, la destrucción de otro puede significar en cierto sentido la propia destrucción. Con esta postulación, Butler explora una respuesta a la cuestión de qué es aquello que nos motiva a salvaguardar y preservar esa vida de otro.

Por otro lado, en este capítulo, vuelve a insistir en una idea que recorre toda la obra y que ya había profundizado en escritos anteriores. Plantea que, si desde el comienzo una vida es considerada duelable, entonces el mundo se organizaría de modo tal de protegerla, de minimizar su precariedad y daño, y de garantizar las condiciones para su desarrollo. La manera de considerar esas vidas, la distribución de la duelidad, repercute en el modo en que se articulan socialmente la salud, el empleo, la alimentación, la vivienda, la vida sexual, la guerra, las prisiones, etc.

El tercer capítulo, "La ética y la política de la no violencia”, busca dilucidar los marcos en los que el término "violencia" adquiere significado, indagando a través de qué producciones y oclusiones lo hace, y con qué fines. En efecto, no es posible justificar la violencia o la no violencia sin antes saber qué es interpretado como tal. Con ese propósito, la filósofa recupera a distintos autores -entre los que incluye a Foucault, Fanon, Benjamin, Cover y Balibar- que complementan su estudio en la comprensión de las formas contemporáneas de racismo y política social.

Los dos primeros ayudan a ver cómo el racismo, de manera más o menos tácita, estructura los discursos sobre la violencia y la no violencia. El esquema racial -un modo de percepción que consiste en un conjunto de preconceptos acríticos sobre los cuerpos- permite distinguir entre esas vidas duelables y no duelables; más aún, entre aquellas vidas que son registradas como tales y las que no, dando lugar a una amplia gama de distinciones. Butler evidencia que ese esquema abre las puertas a una lógica bélica que justifica la agresión -y, en última instancia, el asesinato- como defensa propia. La idea de amenaza de destrucción es la que se encuentra en la base de la decisión de negar la entrada de migrantes en países de Europa, Estados Unidos o Australia. Se vuelve preciso entonces el desmantelamiento de esta clase de fantasías y la crítica a la desigualdad que implican.

Con Benjamin, la filósofa muestra cómo el régimen legal que pretende monopolizar la violencia califica de "violenta" toda amenaza, desafío, cuestionamiento o crítica que se dirige al mismo régimen, al tiempo que subsume su propia violencia como una coerción justificable o fuerza legítima bajo el nombre de "ley". De este modo, la muerte acometida por el Estado se realiza en nombre de la democracia y la justicia, mientras que la violencia no estatal es considerada 
criminal y terrorista. Butler retoma la crítica del autor respecto a estos modos de producción y reproducción de la violencia estatal, pero su intención última y más original es la reinterpretación de la enigmática "violencia divina" benjaminiana. En una lectura poco convencional, la autora propone que el término sirve para nombrar actividades que disputan el monopolio legal de la violencia. Para ella, es posible entender que esta divinidad aquí busca trascender la pretensión omniabarcante de la ley, abriendo un espacio para la resolución extralegal de conflictos. Se trata de habilitar una técnica de comunicación y de intercambio civil, como una alternativa siempre abierta y no violenta de resolver conflictos. En otras palabras, una forma de resistencia no violenta a la violencia estatal.

En el cuarto y último capítulo, "Filosofía política en Freud: guerra, destrucción, manía y facultad crítica”, Butler ahonda en algunas nociones freudianas con las que interactúa en su análisis político. Para ella, la violencia y la no violencia son temas al mismo tiempo políticos y psíquicos, y es en el umbral de estos dos mundos donde la reflexión ética tiene lugar. Freud propone la destrucción como una potencia constitutiva de la psiquis. La filósofa se extiende sobre la evolución de esta noción en la obra freudiana, la que finalmente madura en la idea de una pulsión de muerte. Aun cuando la autora reconozca la imposibilidad de probar dicha tesis, le interesa examinar las respuestas que el psicoanálisis ha dado a la problemática sobre los modos de trabajar con y contra esa potencia destructiva. Evalúa las posibilidades y límites de la función del superyó, como así también las dinámicas del Eros y de las formas de identificación en el tráfico con las motivaciones inconscientes y pulsionales. Esta misma preocupación reaparece en la correspondencia que el psicoanalista austríaco mantuvo con Einstein en los tiempos previos al ascenso del nazismo -que los condujo a ambos al exilio-. ¿Existe alguna pulsión para contrarrestar la pulsión de muerte? ¿Juega la consciencia algún papel en ello?

Quizá la apuesta más interesante de Butler en este estudio es la resignificación de la manía y la advertencia sobre su potencia para el pensamiento político. La manía es una respuesta que encuentra el "yo" ante la propia tiranía que desata contra sí mismo en un estado de crisis melancólica. Se manifiesta cuando una pérdida es internalizada, persiste hostilmente y adquiere un poder capaz de destruir al "yo". Ante esta situación, la manía apela a un mecanismo de desidentificación. El "yo" se esfuerza por tomar distancia de lo perdido y romper los vínculos que lo mantienen atado a ello. La manía es una afirmación de la vida que surge como contestación a una crisis potencialmente letal. Es por este motivo que la filósofa se interesa en esta figura. Se sirve de ella porque abre nuevas posibilidades para pensar la resistencia a la destrucción (a las guerras, a los gobiernos despóticos, a los autoritarismos). Lejos de constituirse en un llamado colectivo a la manía, su pretensión es mostrar que la psiquis cuenta con un modo de distanciarnos de una realidad establecida y naturalizada, de enfatizar el deseo por la vida y buscar resoluciones ante contextos críticos que amenazan con la destrucción.

Frente a las críticas de que una opción por la no violencia es poco realista, débil, ingenua, pasiva o inútil, Butler fuerza los límites del pensamiento de lo posible para optar por un imaginario político que no decline ante los pronósticos desalentadores. En los textos no se propone la no violencia como un principio absoluto, sino como una respuesta apremiante en la lucha contra la violencia en un contexto ética y políticamente ambiguo. La no violencia expone los mecanismos por los cuales la violencia estatal se defiende de las comunidades negras, indígenas, migrantes y disidentes. Esta postura demanda una noción de igualdad que redefina el valor de las vidas frente a los poderes que las acechan, que asuma la interdependencia de ellas, que se comprometa con la opción de que los cuerpos no pueden persistir y desarrollarse por sí solos. La subsistencia del “yo" depende de 
la subsistencia de otras criaturas, humanas y no humanas, y de la preservación del mundo que las sostiene. 